\title{
This Issue: Important Clinical Studies with New Useful Information on Problems Encountered Daily by Family Physicians
}

\author{
Marjorie A. Bowman, MD, MPA, Anne Victoria Neale, PhD, MPH, and \\ Dean A. Seebusen, $M D, M P H$
}

Oh, what an issue! Extra, Extra, Read all about it! Patients deceiving doctors for prescriptions; characteristics of chronic pain seekers in primary care versus specialty settings; potential overuse of antidepressants when depression screening instruments are used; improving smoking quit rates through anger/stress management training; using immunoglobulin $G$ levels to diagnose and follow eradication of Helicobacter pylori; patient- and family-friendly gentle cesarean deliveries; plus the economic impact of family physicians delivering babies . . . quite a line-up this issue. We also provide information on using motivational interviewing techniques for treating depression, correlations between specific chronic illnesses and the receipt of preventive services, and family physicians' knowledge of tests considered overused. (J Am Board Fam Med 2014;27:579-580.)

We all know that patients attempt to and sometimes successfully deceive physicians into writing inappropriate prescriptions. However, the impact is still strong when reading the study of doctor shopping and young adults' attempts to deceive doctors by Stogner et $\mathrm{al}^{1}$. Unfortunately, 1 of 25 young adults reported attempted deception to gain a prescription, some for personal use and some with the intent to sell the drugs. Such deceptions for prescriptions are most often for controlled substances. Recreational drug abusers were more likely to be deceivers. Read and weep: most reported being successful at least once-hopefully the insights here can help providers recognize potential deceptions. In another study, Fink-Miller et $\mathrm{al}^{2}$ compared initial treatment seekers with chronic pain patients in family medicine versus a specialist clinic. The patients were similar based on identical initial risk screening instruments, although those seeing family physicians were younger and actually reported more severe pain. Importantly, there were no significant differences in measured risk of misuse or abuse.

We have 2 articles that present very different aspects of patient- and family-friendly obstetrics:

Conflict of interest: The authors are editors of the JABFM. one from rural Alabama and one from inner-city Boston. Alabama's investment in supporting fellowship training for family physicians has paid off for rural areas in terms of patient convenience (less travel), economics (both the doctors and the communities gained), and possibly better outcomes (untested in this study by Avery et $\mathrm{al}^{3}$ ). Further, it is not every day that this journal receives an article whose lead author is the chair of a department of obstetrics and gynecology! The estimate was almost a $\$ 400$ positive impact for each $\$ 1$ invested. Having fellowship-trained family physicians doing deliveries in rural environments is an all-around winner. The Boston-based article provides a detailed report on the components and implementation of "gentle caesarian" deliveries. This may be an unfamiliar term, but the concept comes alive in the article by Magee et al. ${ }^{4}$

Depression is such an important topic for family physicians that we continue to get excellent manuscripts exploring important intricacies of depression care. For example, Jerant et $\mathrm{al}^{5}$ provide data that strongly suggest we consider the possibility of negative outcomes from depression screening in family physician offices. In a randomized trial of nonmedication treatment for depression, Keeley et $\mathrm{al}^{6}$ successfully trained family physicians in motivational inter- 
viewing techniques, which increased patient change talk and physical activity. Kessler et $\mathrm{al}^{7}$ explored how mental health services are delivered in patient-centered medical homes. In another randomized trial, Yalcin et $\mathrm{al}^{8}$ report that the addition of anger and stress management training improved smoking cessation rates: one-third more smokers quit.

Sadly, almost $20 \%$ of men report perpetrating intimate partner violence. ${ }^{9}$ The men who did so were more likely to have had experience with family violence when they were young, to abuse substances, and to have irritable bowel syndrome and insomnia. This article can potentially help primary care clinicians identify and question these patients sooner to assist with intervention.

The burden of chronic diseases can decrease the rate at which screening tests are accomplished. However, as discovered by Liu et al, ${ }^{10}$ the type of chronic disease seems to have differential effects by screening test, and the associations are not all negative. Cervical cancer screening was most negatively affected. The authors speculate on reasons for this, but even the information presented could trigger readers to consider whether their patients with one or more of these chronic conditions are appropriately up to date for various preventive measures. Mauer et $\mathrm{al}^{11}$ explored how well family physicians know 10 of the tests considered overused by the Choosing Wisely campaign. While reading this, refresh your own knowledge on the recommendations. And, which part of the US Food and Drug Administration drug labels is most read by family physicians? ${ }^{12}$

Cheaper and easier: Wang et $\mathrm{al}^{13}$ report data that supports using immunoglobulin $\mathrm{G}$ levels (a blood test) to both diagnose and follow for eradication of Helicobacter pylori after treatment rather than the urea breath test (more expensive, less convenient).

Chapman and Lauzardo ${ }^{14}$ provide a terrific clinical review on latent tuberculosis that goes beyond what is readily available on the Centers for Disease Control and Prevention's website and provides information that is more specific for the primary care clinician. The information on the newer testing methods may be particularly helpful.

Finally, in a reflections piece, Ventres ${ }^{15}$ provides a reasoned discussion of what it means and how to undertake a "pedagogy of dying" to help our patients and their families with the dying process.

\section{References}

1. Stogner JM, Sanders A, Miller BL. Deception for drugs: self-reported "doctor shopping" among young adults. J Am Board Fam Med 2014;27:583-93.

2. Fink-Miller EL, Long DM, Gross RT. Comparing chronic pain treatment seekers in primary care versus tertiary care settings. J Am Board Fam Med 2014;27:594-601.

3. Avery DM Jr, Hooper DE, McDonald JT Jr, Love MW, Tucker MT, Parton JM. The economic impact of rural family physicians practicing obstetrics. J Am Board Fam Med 2014;27:602-10.

4. Magee SR, Battle C, Morton J, Nothnagle M. Promotion of family-centered birth with gentle cesarean delivery. J Am Board Fam Med 2014;27:695-8.

5. Jerant A, Kravitz RL, Fernandez y Garcia E, et al. Potential antidepressant overtreatment associated with office use of brief depression symptom measures. J Am Board Fam Med 2014;27:611-20.

6. Keeley RD, Burke BL, Brody D, et al. Training to use motivational interviewing techniques for depression: a cluster randomized trial. J Am Board Fam Med 2014;27:621-36.

7. Kessler R, Miller B, Kelly M, et al. Mental health, substance abuse, and health behavior services in patient-centered medical homes. J Am Board Fam Med 2014;27:637-49.

8. Yalcin BM, Unal M, Pirdal H, Karahan TF. Effects of an anger management and stress control program on smoking cessation: a randomized controlled trial. J Am Board Fam Med 2014;27:650-65.

9. Singh V, Tolman R, Walton M, Chermack S, Cunningham R. Characteristics of men who perpetrate intimate partner violence. J Am Board Fam Med 2014;27:666-73.

10. Liu BY, O'Malley J, Mori M, et al. The association of type and number of chronic diseases with breast, cervical, and colorectal cancer screening. J Am Board Fam Med 2014;27:674-86.

11. Maurer D, Stephens M, Reamy B, Crownover B, Crawford P, Chang T. Family physicians' knowledge of commonly overused treatments and tests. J Am Board Fam Med 2014;27:699-704.

12. Sullivan HW, O'Donoghue AC, Aikin KJ. Primary care physicians' use of FDA-approved prescription drug labels. J Am Board Fam Med 2014;27:705-9.

13. Wang D, Chiu T, Chiu KW. Clinical implication of immunoglobulin $\mathrm{G}$ levels in the management of patients with Helicobacter pylori Infection. J Am Board Fam Med 2014;27:687-94.

14. Chapman HJ, Lauzardo M. Advances in diagnosis and treatment of latent tuberculosis infection. J Am Board Fam Med 2014;27:710-8.

15. Ventres W. Educating our patients about life and the end-of-life: toward a pedagogy of dying. J Am Board Fam Med 2014;27:719-22. 